\title{
Affordance: A New Perspective on Functionalism and Teaching English Language Grammar
}

\author{
Niloufar Shahmirzadi \\ Department of Applied Linguistics, Faculty of Foreign Languages, Central Tehran Branch \\ Islamic Azad University, Tehran, Iran
}

\begin{abstract}
The present article argues that English language teaching specifically grammar is inappropriately premised on an outcome-based approach. Thus, it proposes an alternative, affordance-based approach to teaching, learning and using grammar. It also defines as use, agency, and not just structural manipulation for learning the language. In so doing, changing the environment and reconstruction are highly emphasized. That is to say, implicit learning grammar through interaction and practices may concern as the product of communication since language learners can benefit from opportunities for interaction to physical and social world through active engagement with the environment. In this case, classroom affordance is not the only opportunity for the language learning; thus, changing the environment and reconstruction are highly concerned. In this way, learning language is the matter of acting in the world and act upon as the matter of autonomy and agency. This way of learning can also result in implicit consciousness raising while provided with feedback. Thus, language learners can experience a phenomenon in the process of understanding a particular manner.
\end{abstract}

\section{Introduction}

In language learning, because of the limited capacity of the brain in the simultaneous processing of information the same results will not happen. For instance, if two learners learn the same language, they cannot internalize similarly as they experience the phenomenon in different ways; however, this process of learning will enhance if teachers provide students with feedback to discern particular aspect of the language. That is to say, variation theory aids to justify the different aspects of learning and pedagogical implications in order to experience a particular phenomenon.
In this case, Larsen Freeman [1] studied on the first language as a complex system and second language as an ecological phenomenon in which studying cognitive, affective are not considered separately in isolation rather in an interrelated factor underlying second language acquisition processes. Tudor [2]; moreover, explores the deep script of human interaction in a natural environment. Thus, there is a shift from a focus on the acquisition of linguistic structures to language as a semiotic social practice.

\section{A Brief History of Affordance}

In ecology, the concept of affordance derives from the interrelation between an organism and other elements in an ecosystem, which was coined by Gibson [3], an American psychologist in his seminal book about visual perception. It is also defined that 'an affordance of the environment are what it offers the animal, what it provides or furnishes, either for good or ill', it is also related to 'both the environment and the animal'. Because Gibson believed that affordance is 'the complementary of the animal and the environment'. For example, he proposed that a track in the forest affords walking, a surface of water affords swimming, a knee-high surface above the ground affords sitting. As for human beings, by cutting, cleaning, paving, and so on some changes will happen so as to change the affordances.

It is also directly indicated as the interaction between the perception and action. That is to say, perception is the result of the ecological phenomenon rather than a mental capacity. This can be materialized through what niche defined as interpretation of animals, including humans, as the affordance such as substances, medium, objects, so as to act upon them [4]. Some actions; noteworthy, are done automatically like drinking water whereas others need some deep pondering such as finding the solution for a problem.

In applied linguistics, affordance defined in different ways [4], [5]. According to Varela, 
Thompson, and Rosch [6], 'affordances consist in the opportunities for interaction that things in the environment possess relative to sensoriomotor capacities of the animal.' Shotter and Newson [7] indicated as 'demands and requirements, opportunities and limitations, rejections and invitations, enablements and constraints.' Neisser [8] posited affordance as 'relations of possibility between animal and their environments', Forrester [9] noted as 'immediately recognizable projections, predictions and perceived consequences of making this (and not that) utterance at any given time.' In line with that van Lier [10] highlighted the key notions in definition of affordance as 'relations, possibility, opportunity, immediacy, and interaction to what is available to the person to do something with' in which 'it is more accurately action in potential and it emerges as we interact with the physical and social world'.

Stoffregen [11], in Sahin, Cakmak, Dogar, Ugur, and Ucoluk [12], also noted affordances as the emergencies. Stoffregen concluded 'affordances are properties of the animal - environment system, that is, they are emergent properties that do not inhere in either the environment or the animal.' This definition also portrayed as something which emerges as the interaction between environment and individual. Since 'affordance are relations between the abilities of organisms and features of the environment' [13], also in Sahin et al. [12], It is worth mentioning that affordance is not the property of the environment as different individuals have different perceptions of the world; for example, how a gardner can transform trash into art , or a gardener can transform a piece of land into a beautiful garden, or how EFL language learners perceive the social context differently which may result in different social practices. This may influence by the way they perceive the language learning phenomenon in the world.

\section{Affordance as a Tool for Teachers}

The term affordance proposed by Gibson to describe action possibilities [14]; however, it is used with more complex definition todays. It is also defined as the relationship between user and artefact that can be developed as independent components and integrated into any learning environment [15]. Recently, affordance also defined as the potential that teachers perceive in a particular technology tool to support the activities in order to merely use the language [16], [17]. In so doing, affordance gives a holistic picture of seeing possibilities and exploring them in action over time [11] by teacher and students in an appropriate context.
An integral part of affordance refers to 'capacity' to adjust the potential of any tool into actual use in line with the educational objectives [16] which needs to be addressed in pre-service training [18] while in in-service programming teachers still have some problems. The other point here is that a poor understanding of affordances of new tools may be a barrier rather than facilitative in learning since how to use the tools is crucial for them and not why to use the tools. Thus, understanding and identifying the affordances by teachers and the way that such perception can meet defined as integration to language learning classrooms.

\section{Language Learning as an Affordance Phenomenon}

Learning language is completed by artifacts discussed in Socio-Cultural Theory (SCT), in an interaction, Chaos Complexity Theory also proposed the crucial role of language in relation with the people and the world known as Ecological Linguistics (EL) [10]. As a result, language development occurs through making meaning or a semiotic process [19] in which it can be justified through affordance. This in fact defined as the relationship between the organism (learner), and the environment [10]. Thus, affordance defined as the 'relations, possibility, opportunity, immediacy and interaction' or 'what is available to the person to do something with' [10]. It is also argued that affordance emerged as a result of 'participation and use'. Halliday [20] indicated that affordance carries meaning through interaction with physical world [10] which can be accomplished by using language in a meaningful and non-linear way rather than as a result of accumulation of explicit rules [10] in order to verbalize the learned language [21].

To delve into the issue, it is cleared that affordance deals with the language works in the market rather than pure grammarian view. Thus, with this goal grammar is viewed as who the students are, what the students' experience has been, and what the teachers believe would be helpful to them. That is to say, grammar is a skill rather than a body of knowledge along with listening, speaking, reading, and writing. As a result, there is no need for concern on learning grammar since through using grammar in authentic, skills-based model learning can be possible [22].

According to Larsen-Freeman grammar can be considered as a skill rather than a body of knowledge, and in line with that the term 'grammaring' received credit as the fifth skill. Furthermore, 'grammar is learned not with the form of the target language 
rather with the conveyed message' [23] which is in total contrast with the real-life learning experience of language learners [24]. And, as a result of that rarely can language learners recall the structures to use properly inside and outside the classroom [22].

It is worth noting that students' needs determine teacher's decision on how and what to teach in the classroom. It is also crucial to note the context of teaching since EFL language learners need to study grammar so as to use language accurately.

\section{Grammaring versus Grammar}

To accentuate the crucial role of grammar, van Lier [10] posited that language grammar does not merely 'grow' with both triggering from the environment, and does not learn rule by rule. Along with that van Lier [10] emphasized the role of environment which is appreciated by Vygotsky [25] and Piaget [26] as something new will emerge from nothing. This claim strengthen by input hypothesis of Krashen [27] in which through subconscious exposure to language, acquiring the complex structure of language is possible that 'emerged over time' [28]. In this process, restructuring of information in mind will lead into cognitive emergence; however, the assumption that language is a fixed code is not of paramount importance in this study and no attention was given to the role of acquiring language in social interaction. Nunan [24] proposed that 'the linear approach to language acquisition is problematic, and does not reflect what language is currently known about the process of acquisition'. He further noted 'organic' approach as a more consistent way than the linear approach, because the linear approach deals with the premise that one item can be learned at a time; for example, learning simple present, present continuous, simple past, and present perfect move linearly. That is to say, language learning occurs in an active engagement in discoursal encounters which lead into emergence of mastery over sentences.

The term affordance can also define in terms of natural and cultural affordance in which the latter refers to 'historically specific meanings and values' [29]. Indeed, affordance is action potential that further linguistic action is possible based on previous action. Guerrettaz and Johnston [30] added that affordance is 'the process of meaning making', in affordance also 'artifacts such as classroom materials like curriculum, discourse processes and learning' can function to mediate the relationship among teachers, learners, learning curriculum and discourse patterns [30]. Hopper [31] proposed the regularity of grammar emerged out of discourse in an ongoing process which is 'auxiliary stimuli' appropriate in social practice to raise the consciousness of human based on Vygotsky's theory.

\section{Collaborative Online Awareness of Affordance}

In an experimental study, collaborative assessment used to prompt and assess online assessment of student's collaborative writing. In what follows, Table 1 provides a comprehensive overview of learning affordance.

Table 1. Learning Affordances Perceived by Lucy in Wiki

Interview

\section{Generalizable}

Technology tool (wiki)

Can add content to Web page; Can see who has made changes on history page; Can see who is working on the wiki at the same time; Wikis allow for collaboration

Learning: Writing

Can discuss with other Ss in L2 (practice using language); Ss can open their own pages from the central wiki (ownership of writing space)

Specific to this teacher, this context

Teacher Ss could help each other with language focus (e.g., grammar questions)

Learners Offers an internal community (part of Blackboard), compares favorably to Facebook which she describes as too open (e.g., can discuss the weekend)

Allows opportunity for students to reflect on their work over time

Collaboration, but hasn't used it yet as assessments at uni are all individual. Two Ss have used this affordance themselves

Easy to interact with compared to their blog experience

2 Generalizable

Technology tool (wiki): Able to add photos

Learning Ss can open as many pages as they like; Ss can edit their pages; Ss can delete their comments; Allows class discussion to continue out of class 
Specific to this teacher, this context

Teacher Wiki allowed T to keep up to date with what was happening when she was on leave

$\mathrm{T}$ was able to support Ss with problem deleting and restoring pages

Allows $\mathrm{T}$ to be teacher and facilitator but also just to be participant - exploit different voices

Ts are able to share their own personal experience, which encourages Ss to unveil themselves and contributes to making class feel closer

Local support: The negative aspect of being closed as a community was compensated for by having institutional support for wiki

Learners Wiki allows Ss to edit their own work continuously (autobiography). Also lets them delete their own comments (blog didn't allow this)

As a discussion space, wikis seem to allow Ss the opportunity to disagree with the teacher in ways that may not happen in f2f class; Ss wanted to add their pictures to page, since Ts were able to - $\mathrm{L}$ saw this as collaborative

Wiki has been quite reliable/stable from a technology point of view (Didn't know about translation feature)

3 Generalizable

Technology tool (wiki)

Learning Wikis give useful perspective on process can view changes that take place

\section{Specific to this teacher, this context}

\section{Teacher}

Ts can use the wiki to keep track of their work together (e.g., outcomes of meetings, page for literature, makes process visible)

Teacher-controlled central wiki allowed Ts to communicate with Ss (e.g., events)

Was able to extend Ss' understanding and knowledge of cultural elements in relation to texts covered in class - "giving cultural seeds"

Was able to use wiki to encourage Ss' more in-depth reading

Able to link to existing metaphor (of Vespa) in 1st year course - introduced themselves through Vespa photo

Can use history to check on who has deleted/contributed to collaborative tasks

Comments can be cut and pasted to allow for easier assessment (Ss create portfolio based on wiki)

\section{Learners}

Cultural/reading

Ss prompted to explore cultural connections (links, questions asked about text) and add comments on specific wiki page
Social/community

Able to communicate with Ss on other 3 campuses photo riddle worked well as an icebreaker to allow all Ss to participate and consider what other people were saying (had to acknowledge each other)

Able to do collaborative tasks together in groups of ten (mixed campus groups)

Able to share notices on dedicated page for Ss (but they didn't use)

Notes. $\mathrm{T}=$ teacher, $\mathrm{Ss}=$ students

[33] Lucy's Chart of Affordance Adopted from

Karen J. Haines, Unitec

\section{Conclusions}

The results of language studies revealed that the concept of affordance does not necessarily belong to the school world as it may go beyond to understanding of SLA. That is to say, the realization of affordance is both in written and oral discourse with regard to cultural awareness and appropriate language use. In that case, affordance defines as something which affords use, agency, and not merely structural manipulation. It is also proposed that classroom affordance is not the only opportunity for the language learning; thus, changing the environment and reconstruction are highly concerned. In this way, learning language is the matter of acting in the world and act upon as the matter of autonomy and agency. Ziglari [32] emphasized that 'it is better for the teacher to expose the learners to the real and natural settings so that they could perceive their world much better and increase their world knowledge.' Van Lier [4] remarked that 'learning the language' is the same as the way animal learn in the forest; therefore, the ultimate task of teachers is to make them aware of niche as a language learner position in a discourse community so as to convey meaning accordingly.

\section{References}

[1] Larsen-Freeman, D. 'Chaos/complexity Science and Second Language Acquisition’. Applied Linguistics. 1997. 8, 2, 141-165.

[2] Tudor, I. 'Learning to Live with Complexity: towards an Ecological Perspective on Language Teaching'. System. 2003. 31, 1, 1-12.

[3] Gibson, J., J. The Ecological Approach to Visual Perception. Hillsdale, New Jersey: Lawrence Erlbaum. 1986. 
[4] van Lier, L. 'From Input to Affordance: Socialinteractive Learning from an Ecological Perspective’, in J. Lantolf (ed), Sociocultural Theory and Second Language Learning. Oxford: Oxford University Press. 2000.

[5] van Lier, L. 'Ecological-semiotic Perspectives on Educational Linguistics', in B. Spolsky, and F. M. Hult (eds.), The Handbook of Educational Linguistics. Malden, MA: Blackwell. 2008. 596-605.

[6] Varela, F., J., Thompson, E., \& E., Rosch. The Embodied Mind: Cognitive Science and Human Experience. Cambridge. MA, MIT Press. 1991.

[7] Shotter, J., \& J., Newson. 'An Ecological Approach to Cognitive Development: Implicate Orders, joint Action and Intentionality', in G. Butterworth and P. Light (eds), Social Cognition: Studies in the Development of Understanding. Chicago: University of Chicago Press. 1982.

[8] Neisser, U. 'From Direct Perception to Conceptual Structure', in U. Neisser (ed.), Concepts and Conceptual Development: Ecological and Intellectual Factors in Categorization. Cambridge: Cambridge University Press. 1987.

[9] Forrester, M. 'Conversation and Instruction within Apprenticeship: Affordances for Learning’, in P. Ainley and H. Rainbird (eds), Apprenticeship: Towards a New Paradigm of Learning. London: Kogan Page. 1999. 86-97.

[10] van Lier, L. (Ed.). The ecology and semiotics of language learning: A sociocultural perspective (Vol. 3). Boston, MA: Kluwer Academic Publishers. 2004.

[11] Stoffregen, T., A. 'Affordances as Properties of the Animal Environment System', Ecological Psychology. 2003. 15, 115-134.

[12] Sahin, E., Cakmak, M., Dogar, M., Ugur, E., \& G., GUcoluk. 'To Afford or not to Afford: A new Formalization of Affordances toward Affordance-based Robot Control'. Adaptive Behavior. 2007. 154, 447-472.

[13] Chemero, A. 'An Outline of a Theory of Affordances', Ecological Psychology. 2003. 15, 181-

195.

[14] Turner, P. Affordance as context. Interacting with Computers. 2005. 17, 787-800.

[15] Doering, A., Miller, C., \& G., Veletsianos. Adventure learning: Educational, social and technological affordances for collaborative hybrid distance education. The Quarterly Review of Distance Education. 2008. 9, 249-265.

[16] Egbert, J., Akasha, O., Huff, L., \& H. Lee. Moving forward: Anecdotes and evidence guiding the next generation of CALL. International Journal of ComputerAssisted Language Learning and Teaching. 2011. 1, 1-15.
[17] Sharp, S., K. Teachers acquisition of CALL expertise. International Journal of Computer-Assissted Language Learning and Teaching. 2011. 1, 1-16.

[18] Kessler, G. When they talk about CALL: Discourse in a required CALL class. CALICO Journal. 2010. 27, 376392.

[19] Halliday, M., A. Towards a language-based theory of learning. Linguistics and education. 1993. 5, 2, 93-116.

[20] Halliday, M., A., K. Language as social semiotic. London: Arnold. 1978.

[21] Ellis, R., Loewen, Sh., Elder, C., Erlam, R., Philp, J., \& H., Reinders. Implicit and explicit knowledge in second language learning, testing and teaching. Washington, DC. 2009.

[22] Larsen-Freeman, D. Teaching language: From grammar to grammaring. Boston, MA: Heinle. 2003.

[23] Krashen, S., D. Second language acquisition and second language learning. Oxford: Oxford University Press. 1981.

[24] Nunan, D. An oganic approach to the teaching of grammar. Hong Kong Journal of Applied Linguistics. 1996. $1,1,65-86$.

[25] Vygotsky, L., S. Thought and language (rev. ed.). Cambridge, MA: MIT. 1986.

[26] Piaget, J. Success and understanding. Cambridge, MA: Harvard University Press. 1978.

[27] Krashen, S., D. The input hypothesis: Issues and implications. Addison-Wesley Longman Ltd. 1985.

[28] Levine, G., S. Principles for code choice in the foreign language classroom: A focus on grammaring. Language Teaching. 2014. 47, 3, 332-348.

[29] Reed, E., S. James J. Gibson and the psychology of perception. New Haven, CT: Yale University Press. 1988.

[30] Guerrettaz, A., M., \& B., Johnston. Materials in the classroom ecology. The Modern Language Journal. 2013. 97, 3, 779-796.

[31] Hopper, P., J. Emergent grammar. Berkeley Linguistics Society, Berkeley, CA. 1987.

[32] Ziglari, L. 'Affordance and Second Language Acquisition'. European Journal of ScientifiResearch. 2008. 23, 3, 373-379.

[33] Karen J. Haines, Unitec. Learning to Identify and Actualize Affordance in a New Tool. Language Learning \& Technology. 2015. 19,1, 165-180. 